\title{
Cure kinetics of vapor grown carbon nanofiber (VGCNF) modified epoxy resin suspensions and fracture toughness of their resulting nanocomposites
}

\author{
A.T. Seyhan ${ }^{\mathrm{a}, \mathrm{d}}$, Z. Sun $^{\mathrm{a}}$, J. Deitzel $^{\mathrm{a}}$, M. Tanoglu $^{\mathrm{b}, *}$, D. Heider $^{\mathrm{a}, \mathrm{c}}$ \\ a Center for Composite Materials (CCM), University of Delaware, Newark, DE 19716, USA \\ ${ }^{\mathrm{b}}$ Department of Mechanical Engineering, Izmir Institute of Technology, 35430 Urla, Izmir, Turkey

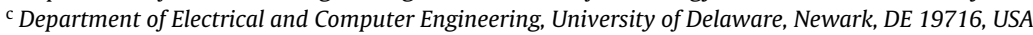 \\ ${ }^{\mathrm{d}}$ Department of Materials Science and Engineering, Anadolu University, Iki Eylul Campus, 26550 Eskisehir, Turkey
}

\section{A R T I C L E I N F O}

\section{Article history:}

Received 19 January 2009

Received in revised form 17 May 2009

Accepted 18 July 2009

\section{Keywords:}

Polymers

Nanostrcutures

Dynamic scanning calorimetry (DSC)

Fracture and toughness

\begin{abstract}
A B S T R A C T
In this study, the cure kinetics of Cycom 977-20, an aerospace grade toughened epoxy resin, and its suspensions containing various amounts (1, 3 and $5 \mathrm{wt} . \%$ ) of vapor grown carbon nanofibers (VGCNFs) with and without chemical treatment were monitored via dynamic and isothermal dynamic scanning calorimetry (DSC) measurements. For this purpose, VGCNFs were first oxidized in nitric acid and then functionalized with 3-glycidoxypropyltrimethoxy silane (GPTMS) coupling agent. Fourier transform infrared (FTIR) spectroscopy was subsequently used to verify the chemical functional groups grafted onto the surfaces of VGCNFs. Sonication technique was conducted to facilitate proper dispersion of asreceived, acid treated and silanized VGCNFs within epoxy resin. Dynamic DSC measurements showed that silanized VGCNF modified resin suspensions exhibited higher heat of cure compared to those with as-received VGCNFs. Experimentally obtained isothermal DSC data was then correlated with Kamal phenomenological model. Based on the model predictions, it was found that silanized VGCNFs maximized the cure reaction rates at the very initial stage of the reaction. Accordingly, an optimized curing cycle was applied to harden resin suspensions. Fracture testing was then carried out on the cured samples in order to relate the curing behavior of VGCNF modified resin suspensions to mechanical response of their resulting nanocomposites. With addition of $1 \mathrm{wt} . \%$ of silanized VGCNFs, the fracture toughness value of neat epoxy was found to be improved by $12 \%$. SEM was further employed to examine the fracture surfaces of the samples.
\end{abstract}

(c) 2009 Elsevier B.V. All rights reserved.

\section{Introduction}

Incorporation of nanofillers into various types of polymers has aroused great attention in materials science to accomplish multifunctional nanocomposites with enhanced mechanical and thermal properties [1-6]. In this manner, carbon nanofibers (CNFs) with large aspect ratio and surface area hold promise for the development of novel polymer based nanocomposites $[3,4,2,6]$. In addition, CNFs possess low cost relative to carbon nanotubes (CNTs). To realize, however, the desired ultimate properties in final composite parts requires the enhancement of poor dispersion state of CNFs, as in the case of CNTs, arising from their inert surfaces and huge surface areas [1-7]. Therefore, some chemical functional groups are grafted onto surfaces of CNFs or CNTs to enhance their compatibility with the surrounding matrix resin [1-8]. Oxidation has been the most common reaction for such chemical modifications because it

\footnotetext{
* Corresponding author. Tel.: +90 232750 7806; fax: +90 2327507825

E-mail address: metintanoglu@iyte.edu.tr (M. Tanoglu).
}

provides a chemical convenience for the conceivable subsequent reactions. More specifically, oxidation reactions generate various functional groups including carboxylic acid, alcohols and ethers. Of all, the most valuable one is carboxylic acid groups. This is because a number of coupling reactions can take place in the presence of carboxylic acid groups, which enables introduction of different types of chemical molecules onto the surfaces of nanofillers $[9,10]$. However, chemical functional groups grafted onto the surfaces of nanofillers may have some considerable influences on the features of composite processing. In particular, they may alter cure kinetics, viscosity and flow behavior of the injected matrix resin in a simultaneous manner [2,6-18].

There have been a number of studies reported in the literature about the influence of nanofillers such as CNTs and CNFs on the cure kinetics of various types of epoxy resins [11-17]. Xie et al. $[9,17]$ investigated the effects of incorporation of CNFs and CNTs on the cure kinetics of epoxy resins by conducting several isothermal DSC measurements. They concluded that the presence of CNTs within the epoxy resin showed more pronounced effects on the cure kinetic parameters of the corresponding epoxy resin as com- 
pared to the presence of CNFs. Bae et al. [10] studied the cure behavior of a liquid crystalline epoxy resin containing carbon black (CB) and CNTs with and without oxidative treatment via DSC measurements. Based upon the predicted kinetic parameters of the autocatalytic equation, they concluded that the activation energies of epoxy resin containing surface treated carbon fillers are lower as compared to those of epoxy resin with as-received carbon fillers.

In fact, nanofillers affect not only the curing behavior of matrix resins but also ultimate mechanical performance of the resulting nanocomposites. Fracture toughness of polymer matrix is of prime importance in response of fiber reinforced composites under mechanical loading. In this manner, incorporation of nano-sized fillers into polymer matrices offers huge potential to achieve final composites with the desired mechanical properties. Gojny et al. [3] reported that the addition of very low content ( $0.1 \mathrm{wt} . \%)$ of CNTs improved the fracture toughness of the epoxy resin by about $42 \%$, while retaining their tensile strength and modulus values. In their another study [2], they showed that glass fiber/0.3 wt.\% DWCNT- $\mathrm{NH}_{2}$ modified epoxy matrix composites have $19 \%$ higher interlaminar shear strength values as compared to composites without nanotube modification.

Among other resins, high performance Cycom 977 epoxy resins have been frequently used in aerospace systems. The resins are available for both prepregs and resin transfer molding (RTM) applications. Cycom 977-20 has been developed for vacuum assisted resin transfer molding (VARTM) application where a relatively low viscosity is required. The attractive features of these thermosetting resins include very good toughness and high $T_{\mathrm{g}}$, holding promise for composites with good mechanical and thermal properties. However, the cure kinetics of this advanced epoxy resin has not been so far investigated in the literature in spite of its exceptional advantages, which encompasses the major scientific motivation of this study.

In the present work, the effect of CNFs with and without silane coupling agent on the cure kinetics of the Cycom 977-20 VARTM epoxy resin was investigated through dynamic and isothermal DSC measurements. Chemical functional groups grafted onto surfaces of CNFs were monitored via FTIR measurements. The influences of CNFs with and without silane treatment on the resin curing behavior were discussed in detail, comparing the experimental findings obtained from DSC measurements with those predicted by the proposed autocatalytic model. Fracture test was further performed on the cured epoxy resin and its resulting nanocomposites containing CNFs with and without silane treatment. The results obtained were then discussed in detail.

\section{Experimental}

2.1. Materials

The elevated VARTM epoxy resin (Cycom 977-20) used in this study was provided from CYTEC engineering materials. Vapor grown carbon nanofibers (VGCNFs) grade PR 19 LHT in a diameter of $100-200 \mathrm{~nm}$ and a length of $30-100 \mu \mathrm{m}$ were obtained from Applied Sciences Inc. According to data provided by the manufacturer, these nanofibers were produced by chemical vapor deposition (CVD) process. Further, they were heated up to $3000^{\circ} \mathrm{C}$ for removal of iron catalyst and graphitization. The product contains less than $1 \mathrm{wt} . \%$ of poly aromatic hydrocarbon (PAH). 3Glycidoxylpropyltrimethoxy silane (GPTMS) coupling agent with purity of $98 \%$ was purchased from Aldrich. Concentrated nitric acid $\left(\mathrm{HNO}_{3}\right)$ and ethanol (99.9 wt.\%) were provided from Fischer Scientific and Merck, respectively.

\subsection{Oxidative treatment of carbon nanofibers}

Carbon nanofibers were oxidized in nitric acid solution via magnetic stirring at $70^{\circ} \mathrm{C}$ for $24 \mathrm{~h}$. The CNFs were ultrasonically treated in water bath at room temperature for $2 \mathrm{~h}$ to divide the agglomerated CNFs into individuals or smaller ones prior to oxidation process. Deionized water was used to wash the filtrate until it had a $\mathrm{pH}$ value of approximate 7 . Then, the CNFs obtained were dried in a vacuum oven at $80^{\circ} \mathrm{C}$ for $24 \mathrm{~h}$.

\subsection{Silanization of carbon nanofibers}

The aim of silanization is to improve the compatibility of CNFs with the corresponding epoxy matrix resin, thus tailoring the fiber/matrix interface. Fig. 1 illustrates the corresponding silane functionalization route followed in this study. A mixture of ethanol and deionized water (4:1) was prepared and its $\mathrm{pH}$ value was subsequently adjusted to about 4 using acetic acid. Afterwards, $1 \mathrm{wt}$.\% of corresponding silane coupling agent was added into the mixture. The solution was stirred to hydrolyze silanes into silanols and then acid treated CNFs (oxidized CNFs) were added into the system. To promote the silanization reaction, CNFs were ultrasonically dispersed within the solution for $2 \mathrm{~h}$ followed by magnetic stirring for $4 \mathrm{~h}$. The silanized CNFs were then filtrated and washed several times with deionized water, ethanol and acetone in sequence. Note that methanol was further added to the filtrate to dilute the residues of silane molecules. The final product achieved was then dried in a vacuum oven at $80^{\circ} \mathrm{C}$ for $24 \mathrm{~h}$ for the formation of siloxane network through a condensation reaction.

\subsection{Surface characterization of carbon nanofibers}

To monitor the oxidation and attachment of silane groups onto the surfaces of CNFs, FTIR investigations were performed on CNF samples. For this purpose, silane treated and as-received CNFs were pressed into a pellet using potassium bromide $(\mathrm{KBr})$ powders and subsequently scanned from 500 to $4000 \mathrm{~cm}^{-1}$ at a resolution of $4 \mathrm{~cm}^{-1}$ using Schimadzu 8201 FTIR spectrometer.

\subsection{Preparation of resin suspensions}

Resin suspensions were prepared by incorporating 1, 3 and 5 wt.\% of CNFs with and without chemical treatment into the epoxy matrix resin. The blends were stirred manually for $10 \mathrm{~min}$ followed by sonication for about $30 \mathrm{~min}$ using a Vibracell VCX 750 sonicator. Here, a pulsed ultrasound was used to disperse the CNFs within the resin. The suspensions were pulsed at the lowest convenient amplitude with high time intervals to avoid instantaneous heating of the resin suspensions, which may lead to initiation of polymerization reaction prior to DSC measurements. The prepared resin suspensions were then subjected to DSC scanning under dynamic and isothermal modes.

\subsection{DSC measurements}

A differential scanning calorimeter (TA instruments Q 100) was employed to investigate the curing behavior of epoxy resins containing CNFs with and without functional groups. Small quantities of the samples (5-10 mg) were loaded onto hermetic aluminum cells for the DSC studies. Measurements were taken under nitrogen flow of $50 \mathrm{ml} \mathrm{min}^{-1}$. To interpret the effect of CNFs on the cure behavior of the epoxy resin system, the epoxy resin suspensions containing various amounts of CNFs ( 1 , $3,5 \mathrm{wt} . \%$ ) with and without silane treatment were first scanned dynamically from 50 to $300^{\circ} \mathrm{C}$ with a heating rate of $2^{\circ} \mathrm{C} \mathrm{min}^{-1}$. Based upon the results obtained, resin suspensions containing $1 \mathrm{wt} . \%$ of as-received, acid treated and silane treated CNFs were further monitored under isothermal DSC scans. Afterwards, the effect of surface modifications on polymerization reaction was comprehensively evaluated based upon the predicted kinetic parameters and activation energies. Isothermal DSC measurements were conducted at various temperatures including 180, 190, 200 and $210^{\circ} \mathrm{C}$. The corresponding polymerization reaction was supposed to be complete when the signal leveled off to the baseline. The total heat of the reaction $\left(\Delta H_{\mathrm{i}}\right)$ was obtained for each corresponding suspension by integrating the area under the peaks of the dynamic or isothermal DSC exotherms. At the end of each isothermal and dynamic run, each sample was cooled to $50^{\circ} \mathrm{C}$ and subsequently reheated up to $300^{\circ} \mathrm{C}$ with a heating rate of $10^{\circ} \mathrm{C} \mathrm{min}^{-1}$ in order to determine their residual heat of reaction $\left(\Delta H_{\mathrm{r}}\right)$.

\subsection{Fracture test}

To investigate fracture behavior of the resulting nanocomposites, the prepared resin suspensions were cured, following the optimized curing cycle depicted in Fig. 2. Fracture testing was then performed according to ASTM D 5045 standard, using Single Edge Notched Beam (SENB) configuration. Please note that the aim of fracture test herein is to associate the observed curing behavior of the resin suspensions with the mechanical response of their resulting nanocomposites. In this manner, rectangular specimens were sectioned from the larger cured epoxy samples and machined to the corresponding specifications stated in accordance with the corresponding standard. A sharp crack was then introduced by tapping on a fresh ultra sharp carbon steel razor blade placed in the notch. The initial crack length was subsequently measured using dark field optical microscopy. The prepared specimens were tested using an Instron testing machine at room temperature. The specimens were loaded with a crosshead speed of $10 \mathrm{~mm} \mathrm{~min}^{-1}$ in a three point bending fixture at a span length of $50 \mathrm{~mm}$. The critical stress intensity factor of the nanocomposites was then calculated by the following equation:

$K_{Q}=\left(\frac{P_{Q}}{B W^{1 / 2}}\right) f(x)$ 


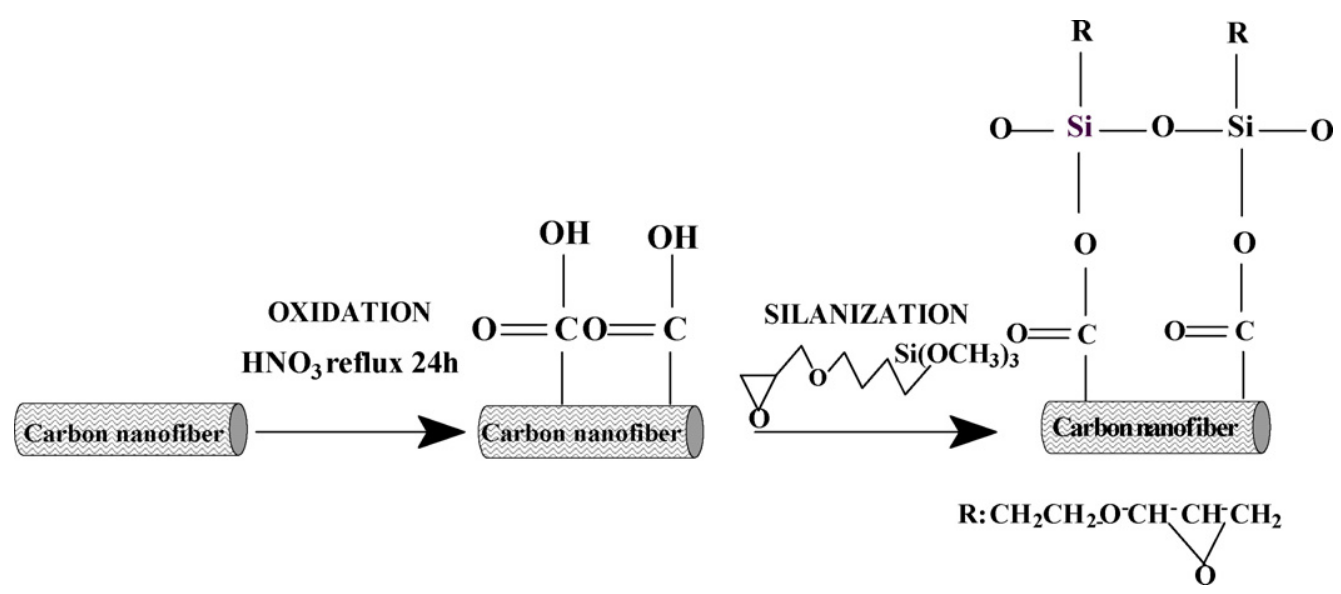

Fig. 1. Schematic of surface functionalization process for CNFs.

where $P_{Q}$ is the failure load, $B$ and $W$ are the specimen thickness and width respectively, and $f(x)$ is the calibration factor described in the corresponding test method.

\section{Cure kinetics approach}

DSC is very practical method to measure both the total heat of a reaction and the reaction rate with respect to time or temperature. The basic kinetic approach for thermosetting polymers is that the heat flow measured via DSC is proportional to the reaction rate, as given below:

$\frac{d \alpha}{d t}=\frac{d H / d t}{\Delta H_{\mathrm{i}}+\Delta H_{\mathrm{r}}}$

where $(d \alpha / d t),(d H / d t)$ and $(\alpha)$ are the reaction rate $\left(\min ^{-1}\right)$, the measured heat flow and extent of reaction, respectively. $\Delta H_{\mathrm{i}}$ is the isothermal heat of reaction obtained from each isothermal scan and $\Delta H_{\mathrm{r}}$ is the residual heat of reaction from subsequent dynamic scan. Please note that $\Delta H_{\mathrm{i}}+\Delta H_{\mathrm{r}}$ comprise the total heat of reaction as well. The extent of reaction is given by the following formula:

$\alpha=\frac{\Delta H_{t}}{\Delta H_{\mathrm{i}}+\Delta H_{\mathrm{r}}}$

where $\Delta H_{t}$ is the heat generated up to time $t$ in an isothermal experiment. The phenomenological model developed by Kamal and Sourour [19] to define the autocatalytic reaction is given as follows:

$\frac{d \alpha}{d t}=\left(k_{1}+k_{2} \alpha^{m}\right)(1-\alpha)^{n}$

where $m$ and $n$ are reaction orders and $m+n$ is the overall order and $k_{1}$ and $k_{2}$ are the rate constants. The rate constants $k_{1}$ and $k_{2}$

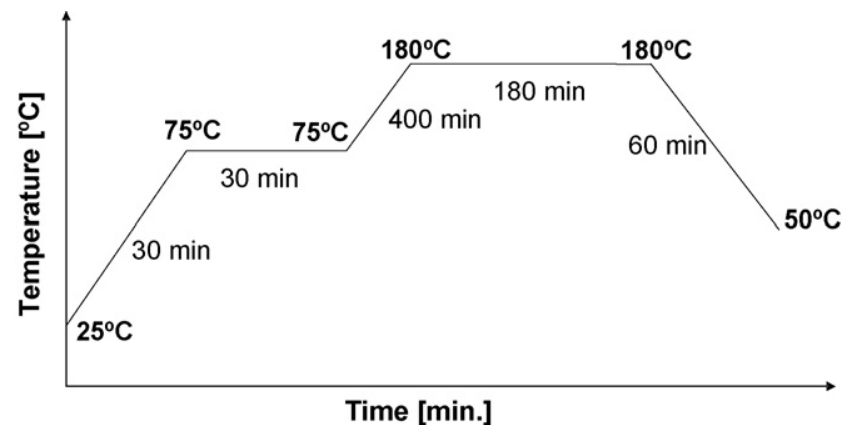

Fig. 2. Optimized curing cycle followed to harden epoxy and its suspensions containing VGCNFs. exhibit two different activation energies and two pre-exponential constants. The constant $k_{1}$ can be simply predicted graphically from the value of reaction rate at the time $t=0$ as given below.

$\left[\frac{d \alpha}{d t}\right]_{t=0}=k_{1}$

Values of $k_{2}, m$ and $n$ can be predicted by non-linear least squares method. The rate constants are assumed to be constant at a given temperature exhibiting temperature dependency based upon the Arrhenius equation which describes how the reaction rate changes with respect to temperature as follows.

$k=A \cdot \exp \left(-\frac{E_{\mathrm{a}}}{R T}\right)$

In the above equation, $A$ is the pre-exponential factor $\left(\mathrm{min}^{-1}\right)$, $E_{\mathrm{a}}$ is the activation energy $\left(\mathrm{J} \mathrm{mol}^{-1}\right), T$ is the absolute temperature and $R$ is the gas constant. Two activation energies $E_{1}$ and $E_{2}$ can be obtained, respectively, from the logarithm of reaction rate constants $\left(\ln k_{1}\right)$ and $\left(\ln k_{2}\right)$ versus the reciprocal of absolute temperature $(1 / T)$. The slopes of these curves are equaled to $(-E / R)$ with an intercept $(\ln A)$. Activation energy values and pre-exponential factors can be then simply predicted.

\section{Results and discussion}

Fig. 3 gives the FTIR spectra of as-received, acid and silane treated CNFs considered in this study. For the as-received CNFs, the band at $1060 \mathrm{~cm}^{-1}$ was attributed to out of plane bending of hydroxyl groups $(-\mathrm{OH})$ on their surfaces resulting from graphization process at elevated temperatures during their production $[20,21]$. The bands at 1715 and $1740 \mathrm{~cm}^{-1}$ were assigned to $C=0$ stretching vibrations of the carboxylic groups [9,20,21]. For the oxidized CNFs, increase in bands of $3000-3500 \mathrm{~cm}^{-1}$ was referred to as $(-\mathrm{OH})$ stretching, indicating that more $(-\mathrm{OH})$ groups on the surfaces of CNFs were induced at the end of oxidative treatment [8]. In the silanized CNFs, the band at $3000-3500 \mathrm{~cm}^{-1}$ was found to be broader and stronger. Furthermore, the band at $1735 \mathrm{~cm}^{-1}$ was more distinctive and two new bands at 2848 and $2914 \mathrm{~cm}^{-1}$ occurred, which are believed to result from stretching of the methylene groups from the GPTMS molecules [20]. The signal at band $888 \mathrm{~cm}^{-1}$ verifies the epoxide groups on the surface of silanized CNFs [21]. All these observations are the ample evidences for proper silane functionalization of the surfaces of CNFs. Fig. $4 \mathrm{a}$ and $\mathrm{b}$ gives the suspension state of CNFs within ethanol solution $\left(0.5 \mathrm{mg} \mathrm{ml}^{-1} \mathrm{CNFs}\right)$ after ultrasonically treated in a water bath for $10 \mathrm{~min}$ and $18 \mathrm{~h}$, respectively. It was observed that 


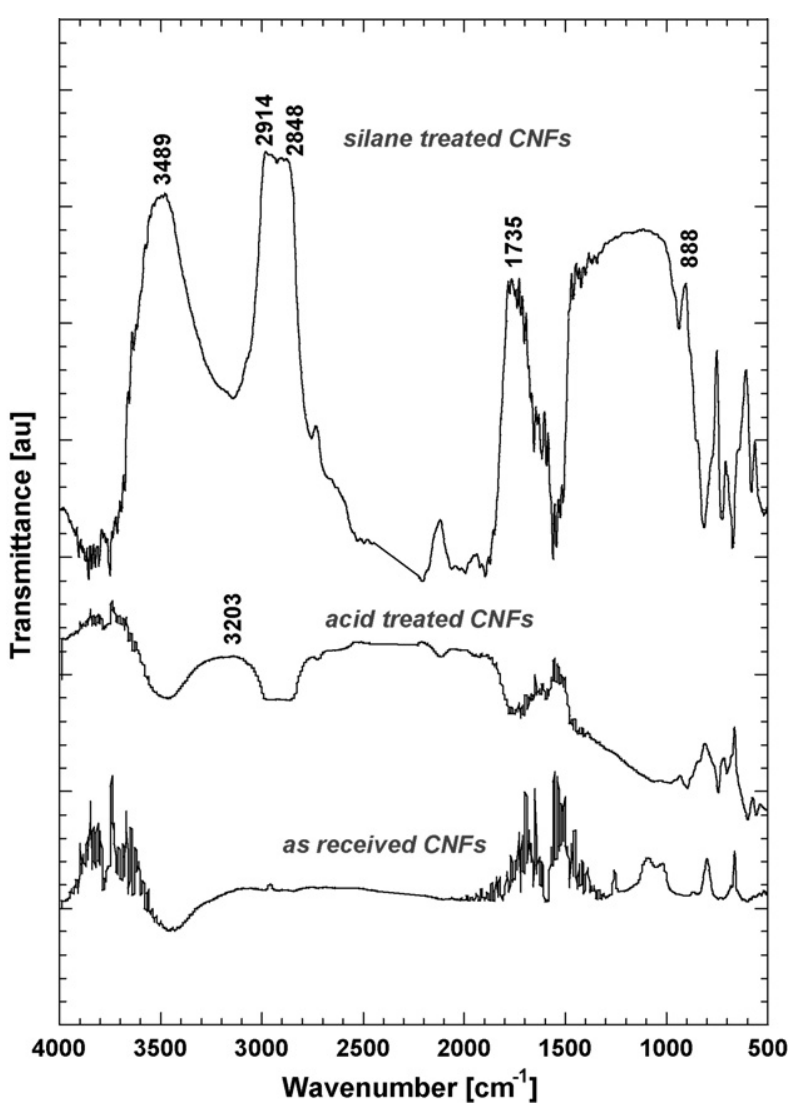

Fig. 3. FTIR spectra of as-received, acid and silane treated carbon nanofibers.

the as-received ones exhibited poor dispersion state and stability due to their inert surfaces, leading to the separations within the solution. However, the silanized CNFs possessed relatively good dispersion state and stability within ethanol due to their improved hydrogen bonding abilities. This can be also considered as a strong evidence for proper silane functionalization of CNF surfaces.

Fig. 5a and b shows the dynamic DSC exotherms of each resin suspension containing different amounts of as-received and silanized CNFs, respectively. For each sample, only one exothermic peak was observed. Nevertheless, no additional peak upon reheating of already scanned samples was detected, indicating that each epoxy resin suspension was properly cured during the initial DSC run.

Table 1 provides the list of calculated heat of cure $(\Delta H)$ and the observed temperature values at maximum exothermic heat flow ( $T_{\mathrm{p}}$, peak temperature) with respect to CNFs with and without

(a)

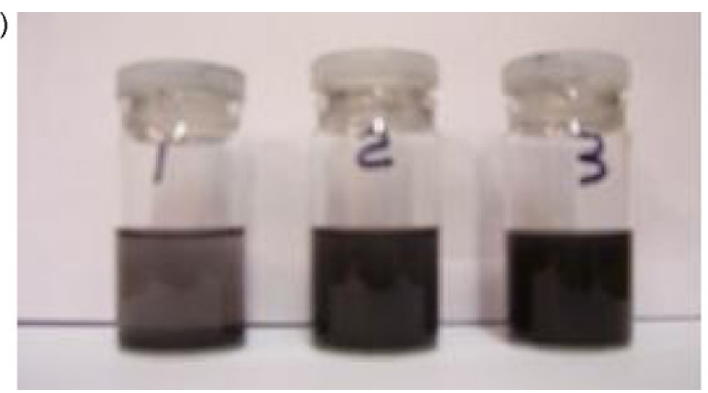

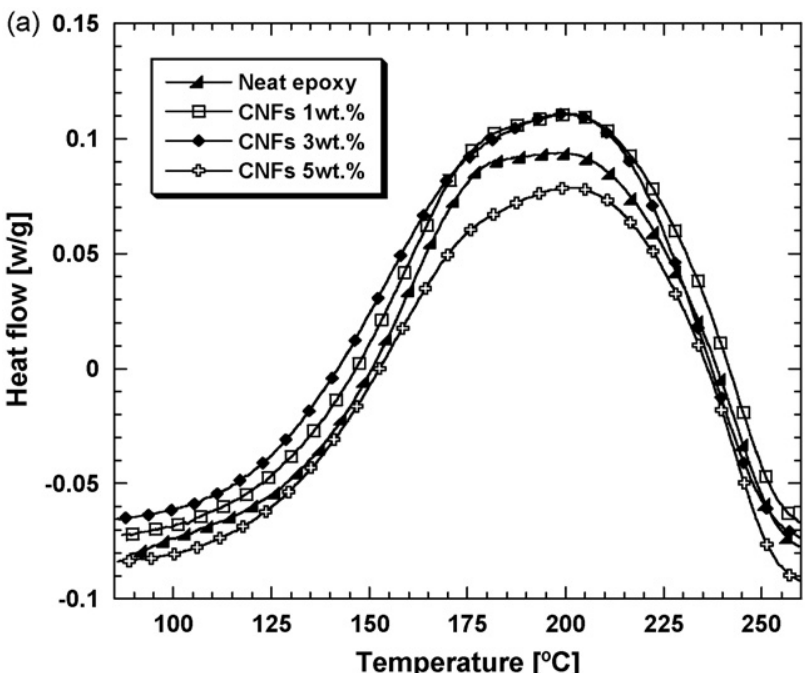

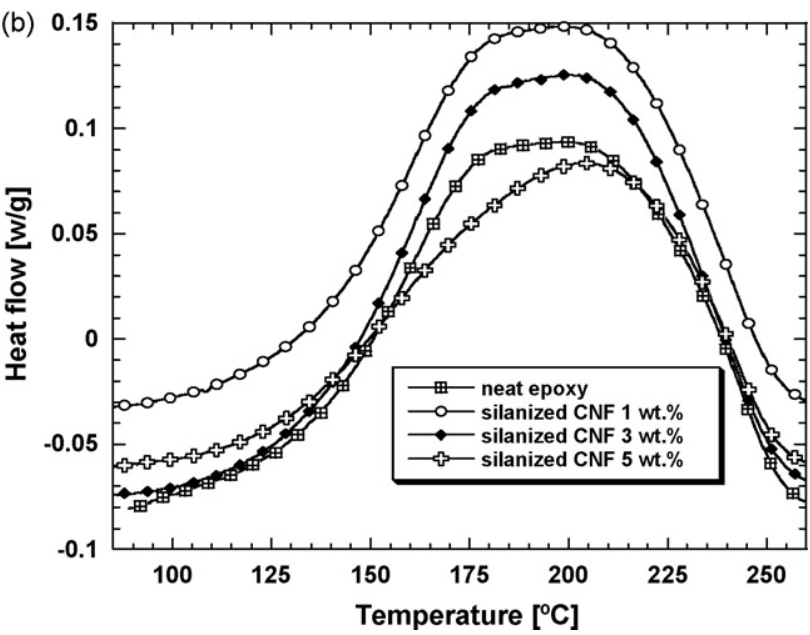

Fig. 5. Dynamic scanning of epoxy resin suspensions containing various amounts of (a) as-received and (b) silanized CNFs.

\section{Table 1}

Heat of cure $(\Delta H)$ and peak temperature $\left(T_{\mathrm{p}}\right)$ of epoxy resin suspensions containing as-received and silanized CNFs at various content.

\begin{tabular}{lll}
\hline Sample & $\Delta H\left(\mathrm{Jg}^{-1}\right)$ & $T_{\mathrm{p}}\left({ }^{\circ} \mathrm{C}\right)$ \\
\hline Neat epoxy & 440 & 200 \\
CNFs (1 wt.\%)/epoxy & 444 & 201 \\
CNFs (3 wt.\%)/epoxy & 446 & 201 \\
CNFs (5 wt.\%)/epoxy & 439 & 202 \\
Silanized CNFs (1 wt.\%)/epoxy & 492 & 196 \\
Silanized CNFs (3 wt.\%)/epoxy & 464 & 201 \\
Silanized CNFs (5 wt.\%)/epoxy & 452 & 203 \\
\hline
\end{tabular}

(b)

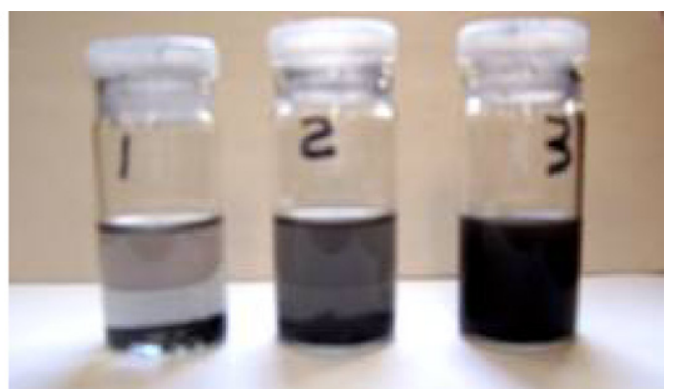

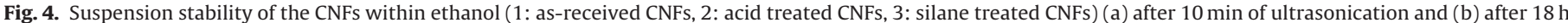
of ultrasonication. 


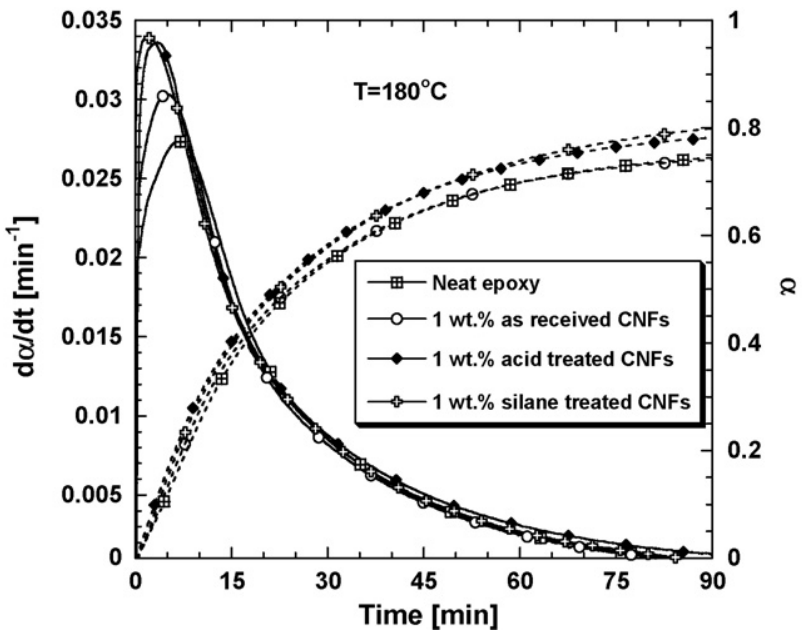

Fig. 6. Reaction rate and degree of conversion for neat epoxy resin and its suspensions containing $1 \mathrm{wt}$ \% of as-received, acid treated and silane treated CNFs as a function of time at isothermal temperature, $T=180^{\circ} \mathrm{C}$.

silane groups at each given loading rate. When handled regardless of types of CNFs, resin suspensions exhibited higher peak temperature with increasing CNFs content. In addition, at each given loading rate, the suspensions containing silanized CNFs possessed higher heat of cure compared to those with as-received ones, which may imply that the extent of cure in suspensions with silane modified CNFs is larger compared to those containing as-received CNFs. In this manner, one can conclude that modified CNFs accelerate the polymerization reaction.

At $1 \mathrm{wt} . \%$ loading rate, the peak temperature of the epoxy resin suspension with silanized CNFs is low relative to that of the neat resin, indicating that the silane groups aid to the polymerization reaction. Therefore, isothermal DSC measurements on the suspensions containing $1 \mathrm{wt} . \%$ of as-received, acid treated and silane treated CNFs were performed to further investigate the effects of the presence of CNFs with and without chemical treatment. Note that the results obtained are reproducible, and that, at 3 and $5 \mathrm{wt} . \%$ loading rates, no significant difference was amusingly observed for the peak temperature values between the resin suspensions con-

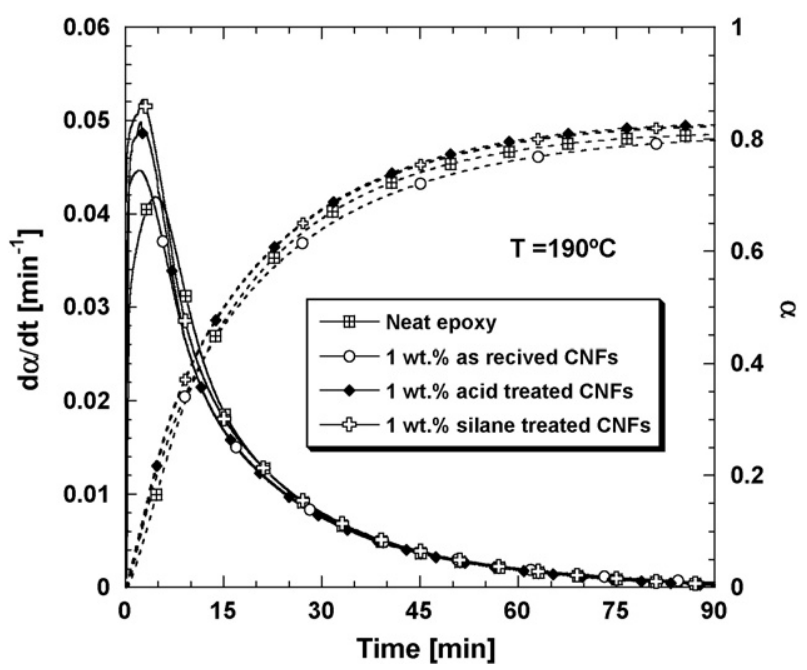

Fig. 7. Reaction rate and degree of conversion for neat epoxy resin and its suspensions containing $1 \mathrm{wt} . \%$ of as-received, acid treated and silane treated CNFs as a function of time at isothermal temperature, $T=190^{\circ} \mathrm{C}$

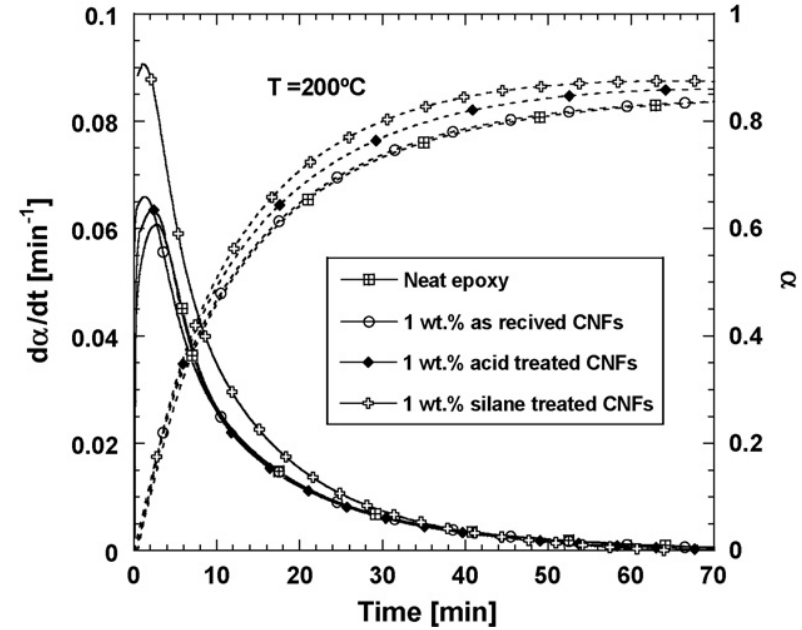

Fig. 8. Reaction rate and degree of conversion for neat epoxy resin and its suspensions containing $1 \mathrm{wt} . \%$ of as-received, acid treated and silane treated CNFs as function of time at isothermal temperature, $T=200^{\circ} \mathrm{C}$.

taining silanized CNFs and those with as-received CNFs. This may be due to gradually increasing degree of agglomeration, as the CNF content in the resin system increased.

Figs. 6-9 provide the experimental results of cure reaction rate and the extent of reaction (degree of conversion) in isothermal mode as a function of time at different temperatures $(180,190$ 200 and $210^{\circ} \mathrm{C}$ ) for the neat epoxy resin and its corresponding suspensions containing $1 \mathrm{wt} . \%$ of as-received, acid treated and silane treated CNFs, respectively. It was eventually observed that the initial reaction rates were altered, depending on the type of CNFs incorporated into epoxy resin. At each applied temperature, the shortest time to the maximum reaction rate as well as the highest reaction rate was obtained from the resin suspension containing silane treated CNFs. Moreover, final extent of reaction increases with temperature and the suspension containing as-received CNFs do not show any significant difference in final conversion values as compared to the neat epoxy resin. In addition, the suspensions that contain acid treated and silane treated CNFs exhibited slightly larger final conversion values as compared to the neat epoxy resin. It is evident that functional epoxide end groups of the

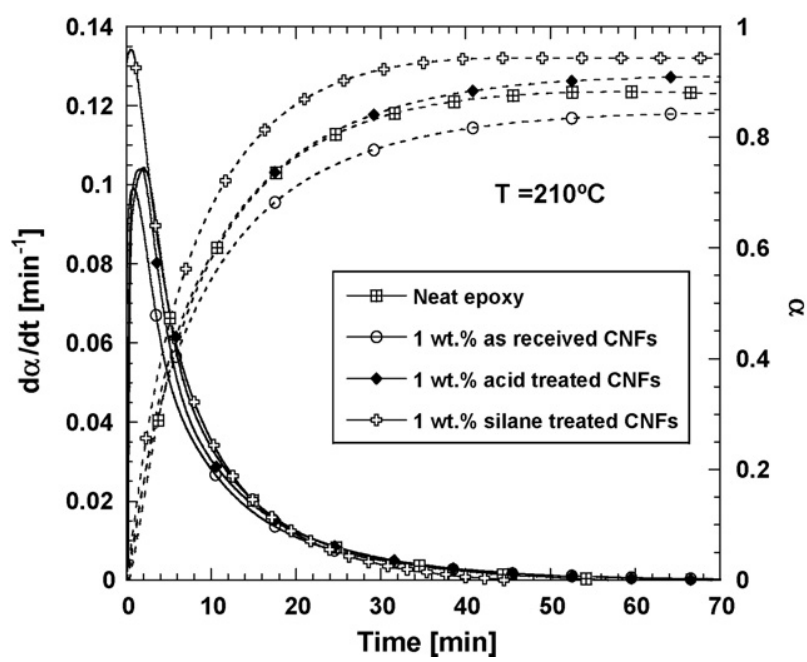

Fig. 9. Reaction rate and degree of conversion for neat epoxy resin and its suspensions containing $1 \mathrm{wt} . \%$ of as-received, acid treated and silane treated CNFs as a function of time at isothermal temperature, $T=210^{\circ} \mathrm{C}$ 
Table 2

Isothermal kinetic parameters obtained from Kamal equation.

\begin{tabular}{|c|c|c|c|c|c|c|c|}
\hline Sample & $T\left[{ }^{\circ} \mathrm{C}\right]$ & $k_{1}\left[\mathrm{~min}^{-1}\right]$ & $k_{2}\left[\min ^{-1}\right]$ & $m$ & $n$ & $m+n$ & $\alpha_{\mathrm{f}}$ \\
\hline \multirow{4}{*}{ Neat epoxy } & 180 & 0.021 & 0.112 & 1.10 & 1.91 & 3.01 & 0.75 \\
\hline & 190 & 0.040 & 0.121 & 1.09 & 1.82 & 2.91 & 0.82 \\
\hline & 200 & 0.065 & 0.156 & 1.02 & 1.64 & 2.66 & 0.83 \\
\hline & 210 & 0.085 & 0.223 & 0.96 & 1.57 & 2.53 & 0.88 \\
\hline \multirow{4}{*}{ As-received CNFs/epoxy } & 180 & 0.023 & 0.103 & 1.13 & 1.86 & 2.99 & 0.75 \\
\hline & 190 & 0.039 & 0.124 & 1.18 & 1.75 & 2.93 & 0.80 \\
\hline & 200 & 0.063 & 0.157 & 1.12 & 1.56 & 2.68 & 0.83 \\
\hline & 210 & 0.084 & 0.221 & 0.98 & 1.58 & 2.56 & 0.84 \\
\hline \multirow{4}{*}{ Acid treated CNFs/epoxy } & 180 & 0.026 & 0.116 & 1.07 & 1.81 & 2.88 & 0.78 \\
\hline & 190 & 0.043 & 0.126 & 0.97 & 1.72 & 2.69 & 0.83 \\
\hline & 200 & 0.068 & 0.179 & 0.93 & 1.54 & 2.47 & 0.85 \\
\hline & 210 & 0.087 & 0.241 & 0.91 & 1.49 & 2.40 & 0.91 \\
\hline \multirow{4}{*}{ Silane treated CNFs/epoxy } & 180 & 0.028 & 0.118 & 1.04 & 1.77 & 2.81 & 0.80 \\
\hline & 190 & 0.045 & 0.131 & 0.94 & 1.68 & 2.62 & 0.83 \\
\hline & 200 & 0.071 & 0.184 & 1.16 & 1.51 & 2.67 & 0.87 \\
\hline & 210 & 0.091 & 0.262 & 0.99 & 1.38 & 2.37 & 0.95 \\
\hline
\end{tabular}

Table 3

Activation energies and pre-exponential factors for the suspensions with different types of CNFs.

\begin{tabular}{llllr}
\hline Sample & $E_{1}\left(\mathrm{~kJ} \mathrm{~mol}^{-1}\right)$ & $E_{2}\left(\mathrm{~kJ} \mathrm{~mol}^{-1}\right)$ & $\ln A_{1}$ & $\ln A_{2}$ \\
\hline Neat epoxy & 54.79 & 41.96 & 18.89 & 8.87 \\
As-received CNFs/epoxy & 52.55 & 46.11 & 17.06 & 10.23 \\
Acid treated CNFs/epoxy & 51.34 & 47.25 & 16.15 & 10.01 \\
Silane treated CNFs/epoxy & 45.42 & 49.52 & 15.78 & 10.92 \\
\hline
\end{tabular}

silane attached onto surfaces of CNFs modify the cure reaction of the epoxy matrix to some extent.

The cure kinetic parameters for each type of resin suspension were predicted according to the autocatalytic model, details of which were already given above. In this manner, $k_{2}, m$ and $n$ were calculated based on the Levenberg-Marquardt non-linear regression method. Table 2 shows the predicted cure kinetic parameters for the neat epoxy and its suspensions with different types of CNFs. As stated in the table, for the neat epoxy resin and its suspensions, the values of $k_{1}$ and $k_{2}$ increased with increasing isothermal curing temperature and values of $k_{2}$ were always greater than those of $k_{1}$. Since $k_{1}$ is related to the early stage of the cure reaction and $k_{2}$ affects the cure reaction after initial autocatalytic stage, the impact

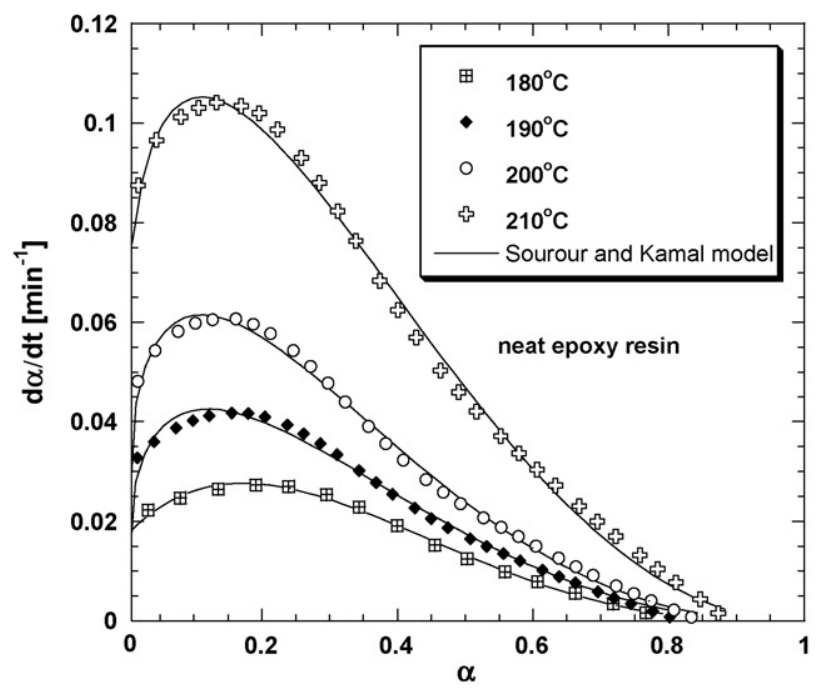

Fig. 10. Measured reaction rates and those predicted by Sourour and Kamal model for neat epoxy resin at various isothermal temperatures as a function of conversion. of surface modification of CNFs on chemical interactions is likely to be higher in the early stage of polymerization reaction. This is probably due to improved thermal conductivity of the epoxy resin as well as reduced resin molecular mobility attributable to large specific surface area of CNFs with huge aspect ratio. In addition, the $m+n$ values were found to decrease with temperature and the lowest sum of $m+n$ values were obtained from the suspension containing silanized CNFs. Based upon two kinetic constants, the two activation energies ( $E_{1}$ and $\left.E_{2}\right)$ as well as pre-exponential factors $\left(\ln A_{1}\right.$ and $\left.\ln A_{2}\right)$ were calculated by plotting $\ln k_{1}$ and $\ln k_{2}$ values against $1 / T$. The predicted values were listed in Table 3 . For comparison, any type of resin suspension exhibited lower activation energies for $k_{1}$ values as compared to those for $k_{2}$ values. At the very initial stage of the reaction, activation energies $\left(E_{1}\right)$ were found to decrease with surface treatment of CNFs, while those $\left(E_{2}\right)$ for later stage of reactions were observed to increase with surface treatment. In addition, of all the $E_{1}$ values, the lowest one belongs to the resin suspension containing silanized CNFs which exhibited the highest $E_{2}$ values at the same time. This implies that silane treated CNFs accelerate the cure reaction of the epoxy system at its very initial stage.

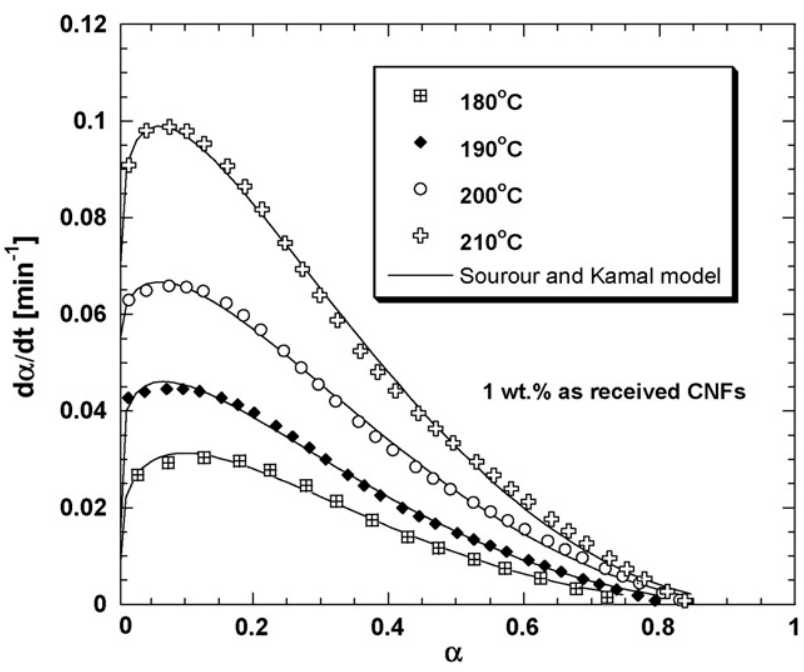

Fig. 11. Measured reaction rates and those predicted by Sourour and Kamal model for epoxy resin containing as-received CNFs at various isothermal temperatures as a function of conversion. 


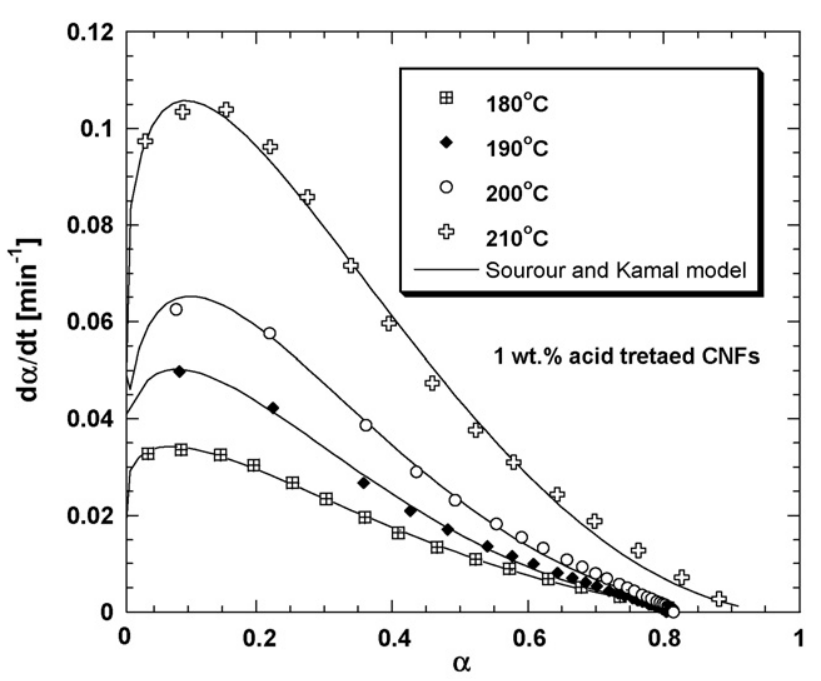

Fig. 12. Measured reaction rates and those predicted by Sourour and Kamal model for epoxy resin containing acid treated CNFs at various isothermal temperatures as a function of conversion.

Figs. 10-13 compare the experimentally determined reaction rates and those predicted by the proposed kinetic model with respect to degree of conversion for neat epoxy resin and its related suspensions containing as-received, acid treated and silane treated CNFs, respectively. As seen in the figures, very good agreement was achieved between the experimental findings and the predicted values over the complete isothermal curing temperatures.

Fig. 14 shows the fracture toughness of the resulting nanocomposites as a function of weight content of CNFs with and without silane treatment. In general, regardless of weight content of CNFs or silane groups, it seems that presence of CNFs did not contribute, significantly, to fracture toughness of the neat epoxy matrix. However, nanocomposites with $1 \mathrm{wt} . \%$ of silanized CNFs exhibited slightly higher (almost 12\%) fracture toughness values as compared to the neat epoxy. Fig. 15a-c depicts the SEM images showing the fracture surfaces of epoxy nanocomposites containing 1, 3 and $5 \mathrm{wt}$.\% of silanized CNFs, while Fig. 15d-f gives the SEM fracture surfaces of epoxy nanocomposites with as-received CNFs at the same loading rates. As seen in the figures, in general, the silanized CNFs have uniform distribution, thus having better compatibility with

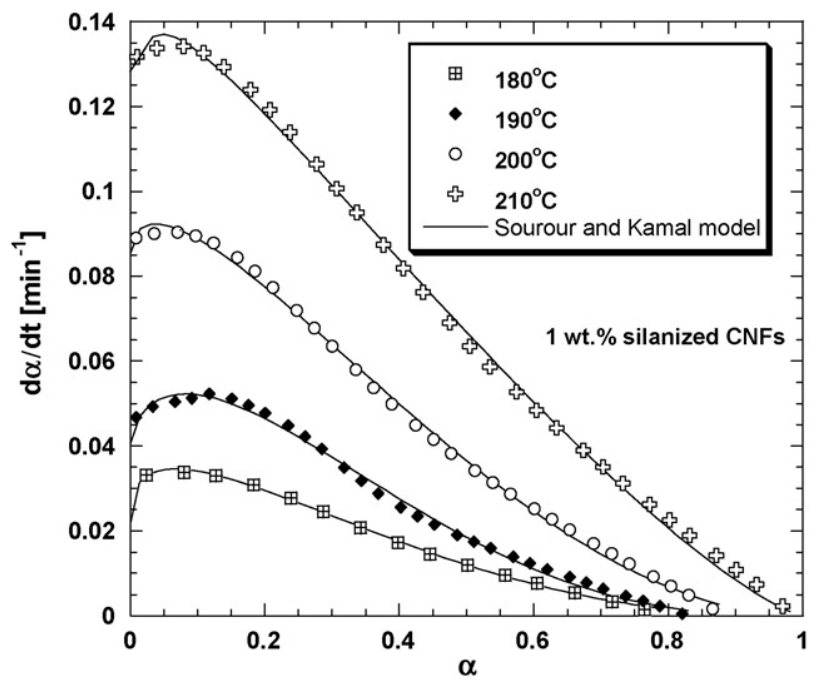

Fig. 13. Measured reaction rates and those predicted by Sourour and Kamal model for epoxy resin containing silane treated CNFs at various isothermal temperatures as a function of conversion.

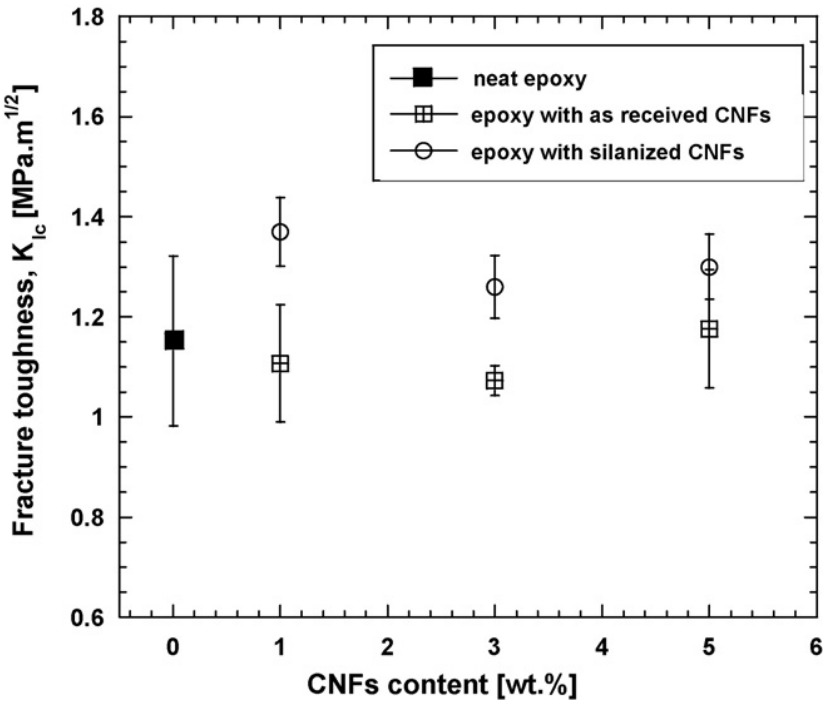

Fig. 14. Fracture toughness of the resulting nanocomposites with respect to weight content of CNFs with and without silane treatment.

the epoxy matrix resin, whereas the as-received ones showed relatively dense agglomerates within the matrix resin. This implies that silane functional groups grafted onto the surfaces of CNFs promoted dispersion state of CNFs within the epoxy resin to some extent, enhancing the interfacial interactions in between. Please note that agglomeration tendency of CNFs due to their huge surface area and aspect ratio limits ultimate performance of their resulting nanocomposites. It is for this reason that, regardless of silane groups, nanocomposites containing 3 and 5 wt.\% of CNFs exhibited lower fracture toughness values as compared to those with $1 \mathrm{wt} . \%$ of CNFs. As seen in Fig. 15e, regions of high content of debonded individual CNFs without silane modification are highly visible at $3 \mathrm{wt} . \%$ loading rate. However, at the same loading rate (Fig. 15b), despite agglomeration, epoxy coated surface of silanized CNFs is observable. The same tendency is also valid for nanocomposites at $5 \mathrm{wt} . \%$ loading rate such that the surfaces of agglomerated CNFs with silane groups are almost entirely coated with epoxy resin (Fig. 15c), while agglomerates of as-received CNFs showed very weak bonding with the surrounding matrix resin. This is why relatively high fracture toughness values were obtained from nanocomposites with silanized CNFs. In addition, based on the SEM images, it is likely that some particular regions of high void volume content, especially around relatively large agglomerates of CNFs regardless of silane groups, may have occurred in the final composite parts, even despite accurate degassing of the epoxy resin prior to curing process. This is because viscosity of the epoxy resin is too high to facilitate proper blending of CNFs with epoxy resin, particularly at any temperature below $75^{\circ} \mathrm{C}$, as depicted in the curing cycle. This may be the most important reason that, regardless of silanized or as-received CNFs, relatively low fracture toughness values were obtained from nanocomposites containing CNFs higher than $1 \mathrm{wt} . \%$.

In brief, the results obtained from fracture testing show great consistency with those obtained from DSC measurements such that incorporation of $1 \mathrm{wt}$ \% of silanized CNFs is highly beneficial to alteration of ultimate performance of the corresponding epoxy resin. At loading rates higher than $1 \mathrm{wt} . \%$, sonication technique seems incapable of dispersing CNFs homogeneously within epoxy resin independent of silane groups. In addition, regardless of degree of agglomeration, silane molecules with epoxide end groups over the surfaces of CNFs were found to enhance the compatibility between CNFs and epoxy resin, tailoring the chemical interactions at the interface in between to some extent. 

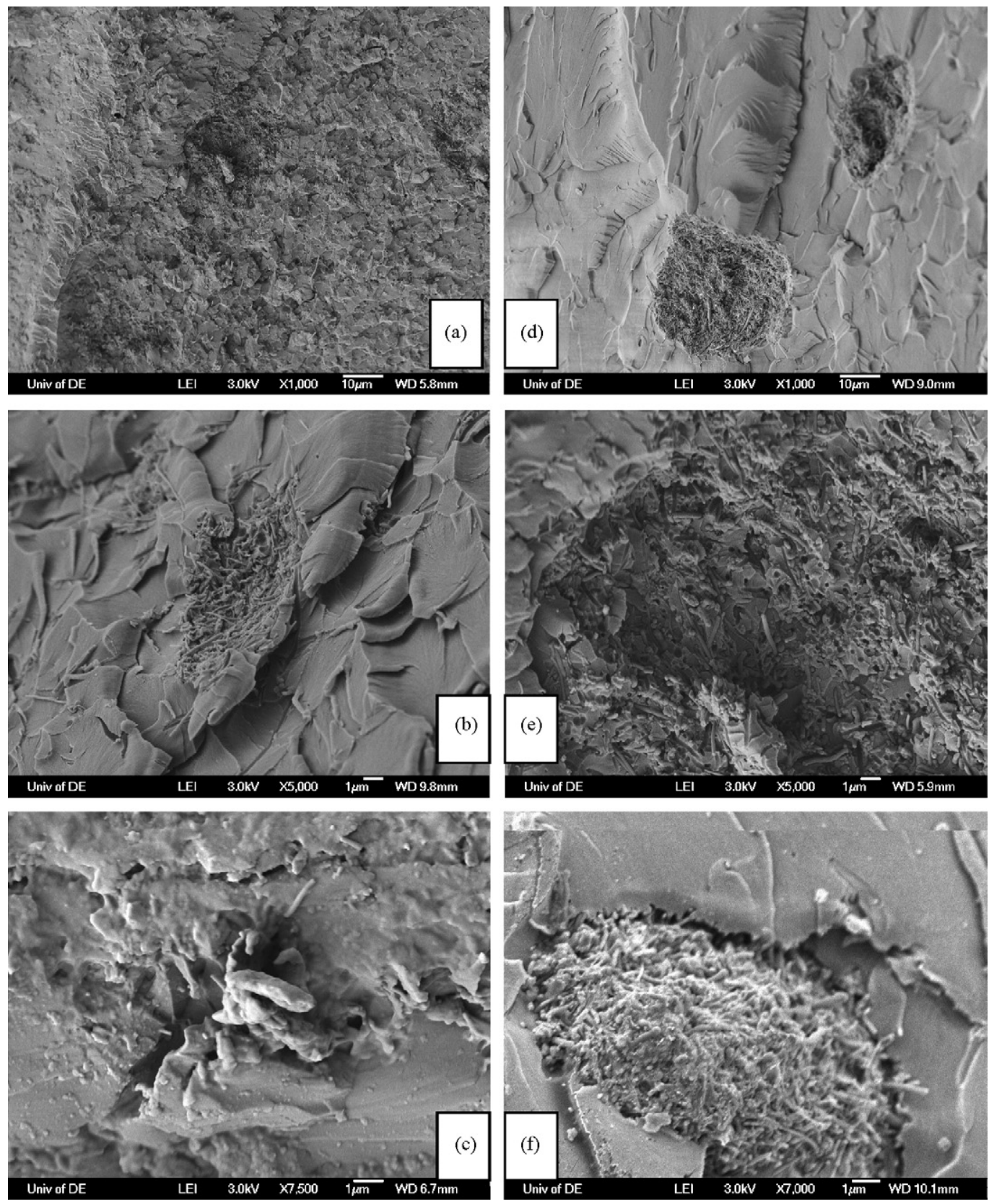

Fig. 15. SEM images of fracture surfaces of nanocomposites (a-c refer to 1,3 and 5 wt.\% of silanized CNFs and d-f refer to 1,3 and 5 wt.\% of as-received CNFs).

\section{Conclusions}

In this study, the vapor grown carbon nanofibers were oxidized in nitric acid solution and subsequently treated with silane coupling agents containing epoxide functional groups were developed. FTIR was used to monitor the functional groups attached over the surfaces of CNFs by these reactions. Afterwards, various amounts of CNFs (1,3 and 5 wt.\%) were subsequently blended with an elevated VARTM epoxy resin using sonication technique. The effects of CNFs with and without treatment upon the cure kinetic behavior of epoxy resin suspensions were investigated conducting DSC measurements in both dynamic and isothermal modes. In the dynamic DSC measurements, it was revealed that resin suspension with $1 \mathrm{wt}$.\% of silanized CNFs exhibited lower peak temperature as well as higher heat of cure as compared to neat epoxy resin and its suspensions with as-received and acid treated CNFs. SEM examination showed that the silane surface treatment improved the dispersion state and stability of CNFs within the corresponding epoxy resin. The isothermal DSC measurements performed on the resin suspensions containing $1 \mathrm{wt} . \%$ of as-received, acid treated and silane treated CNFs showed that the initial rate of cure reaction rate increased with surface treatment of CNFs and maximum reaction rates obtained from resin suspension with silanized CNFs at each isothermal curing temperature. In comparison, all type of resin suspensions exhibited lower activation energies for $k_{1}$ values as compared to those for $k_{2}$ values. Moreover, $E_{1}$ values for resin suspensions were reduced with surface treatment and the lowest one was obtained from the suspension with silanized CNFs which showed also the highest $E_{2}$ values. Furthermore, fracture toughness test was performed on the neat epoxy resin and its nanocomposites with silanized and as-received CNFs. It was found that the addition of $1 \mathrm{wt} . \%$ of silanized CNFs improved the fracture toughness of the epoxy resin by $12 \%$, which is proportional to the findings obtained from DSC measurements. Based on the findings obtained, it was 
concluded that attachment of epoxide end groups containing silane molecules to surfaces of CNFs enhanced the compatibility between CNFs and epoxy resin.

\section{Acknowledgements}

This work was supported by the Office of Naval Research through the project (N00014-02-1-0811) Advanced Materials Intelligent Processing Center at the Center for Composite Materials (CCM), University of Delaware. The authors also wish to thank Abdel Abusafieh and Rick Price from Cytec Industries Inc., for providing the toughened epoxy resin.

\section{References}

[1] F.H. Gojny, K. Schulte, Compos. Sci. Technol. 34 (2004) 2303.

[2] F.H. Gojny, M.H.G. Wichmann, B. Fiedler, K. Schulte, Compos. Sci. Technol. 65 (2005) 2300.

[3] F.H. Gojny, J. Nastalczyk, Z. Roslaniec, K. Schulte, Chem. Phys. Lett. 370 (2003) 820 .
[4] F.H. Gojny, M.H.G. Wichmann, U. Köpke, B. Fiedler, K. Schulte, Compos. Sci. Technol. 34 (2004) 2363.

[5] A.T. Seyhan, F.H. Gojny, M. Tanoglu, K. Schulte, Eur. Polym. J. 43 (2007) 374.

[6] A.T. Seyhan, F.H. Gojny, M. Tanoglu, K. Schulte, Eur. Polym. J. 43 (2007) 2836.

[7] J. Sandler, M.S.P. Schaffer, T. Prase, W. Bauhofer, K. Schulte, A.H. Windle, Polymer 40 (1999) 5967.

[8] J.D. Fidelus, E. Wiesel, F.H. Gojny, K. Schulte, H.D. Wagner, Compos. A 36 (2005) 1555.

[9] H. Xie, B. Liu, Q. Sun, Z. Yuan, J. Shen, R. Cheng, J. Polym. Sci. B: Polym. Phys. 96 (2005) 329.

[10] B. Joonwon, J. Jyongsik, H.Y. Seong, Macromol. Chem. Phys. 203 (2002) 2196.

[11] D. Puglia, L. Valentini, J.M. Kenny, J. Appl. Polym. Sci. 88 (2003) 452.

[12] J.A. Kim, D.G. Seong, T.J. Kang, J.R. Youn, Carbon 44 (2006) 1898.

[13] Y.S. Song, J.R. Youn, Carbon 43 (2005) 1378.

[14] P. Pötsche, A.R. Battachyya, A. Janke, Eur. Polym. J. 40 (2004) 137.

[15] I.A. Kinloch, S.A. Roberts, A.H. Windle, Polymer 43 (2002) 7483.

[16] O. Gryschuck, J.K. Kocsis, R. Thomann, Z. Kanya, I. Kiricsi, Compos. A 37 (2006) 1252.

[17] H. Xie, B. Liu, Q. Sun, Z. Yuan, J. Shen, R. Cheng, J. Polym. Sci. B 42 (2004) 3701.

[18] G. Ghaemy, M.H. Khandani, Eur. Polym. J. 34 (1998) 477.

[19] M.R. Kamal, S. Sourour, Polym. Eng. Sci. 13 (1973) 59.

[20] P.C. Ma, J.K. Kim, B.Z. Tang, Carbon 44 (2006) 3232.

[21] D.W. Mayo, F.A. Miller, R.W. Hannah, Course Notes on Interpretation of Infrared and Raman Spectra, John Wiley Sons, Canada, 2003, pp. 300-325. 